\title{
Should you first cure your ignorance, healthcare professionals?
}

\section{Chiara Gusmini}

\section{MY BACKGROUND}

I am a 38-year-old woman and I have lived for 25 years with chronic pain. I've never hidden it from anybody-I sought help everywhere, but no-one was able to help me to identify the nature of my condition. I learnt strategies to manage my pain by myself until I got unexpectedly introduced to the current best evidence-based management for my condition, which changed my life significantly.

\section{HOW MY PERSISTENT PAIN STARTED}

My story started when I was 12 years old, when I was pushed to the ground outside school and fell on my back. I believe that that fall was the beginning of my persistent pain. Over the following years, persistent spinal pain was diagnosed as 'growth pains'. When I approached my twenties, my pain was widespread. I suffered from widespread pain in my head, neck, back, arms, legs and bowel, as well as insomnia. My pains were not visible on X-rays, MRI scans, or detectable by blood tests, and I was the only one who could perceive them. Doctors and healthcare professionals concluded that my pains were in my mind.

\section{INITIAL TREATMENTS AND DIAGNOSES}

The medicines I was prescribed did not work and, obviously, this situation made me rather anxious. Anxiety then became a problem and I felt I was being blamed for all my aches and pains. I was not improving with any of the treatments attempted (massage, manipulations, laser therapy, diathermy, acupuncture, etc), so it was inferred that my psychological fragility caused all this. The word 'fibromyalgia' then entered my life thanks to a doctor who was sure that my suffering could not be exclusively psychological. Clearly this was an important milestone for me, although having a 'specific' diagnosis did not change my quality of life or my pain. I had a label though, and it was reassuring. However, my pains and the way people (friends, relatives, physios, doctors and trainers) looked at me remained the same: fibromyalgia or not, I was a psychopathic plaintive. I

Correspondence to Chiara Gusmini, Italian Patient, Presezzo 24030, Italy; chiara@chiaragusmini.it realised that, although my pain was not life-threatening, it was badly affecting the quality of my life.

\section{HOW I LEARNT TO SELF-MANAGE}

Gradually I began to realise that, if no-one was able to help me, I had to help myself. I found a psychologist with whom I discussed my pain, my perceptions around it, its 'sense' and 'meaning'. My goal was no longer to eliminate the pain, but to cope with it without crashing. I discovered a number of stratagems to alleviate some pain (such as using heat and meditation), and the ultimate goal was to somehow become stronger than the pain.

I also looked for educational material on fibromyalgia and chronic pain, but I often ran into incomprehensible information including articles which were very unhelpful. I therefore decided to focus on my well-being, and at this point an unexpected miracle happened. I was determined to physically get back on my feet, and realised that I needed a 'stronger' body. All of the years spent listening to doctors advising me not to move or exercise had made me weak and unfit, and therefore I was no longer willing to follow their advice.

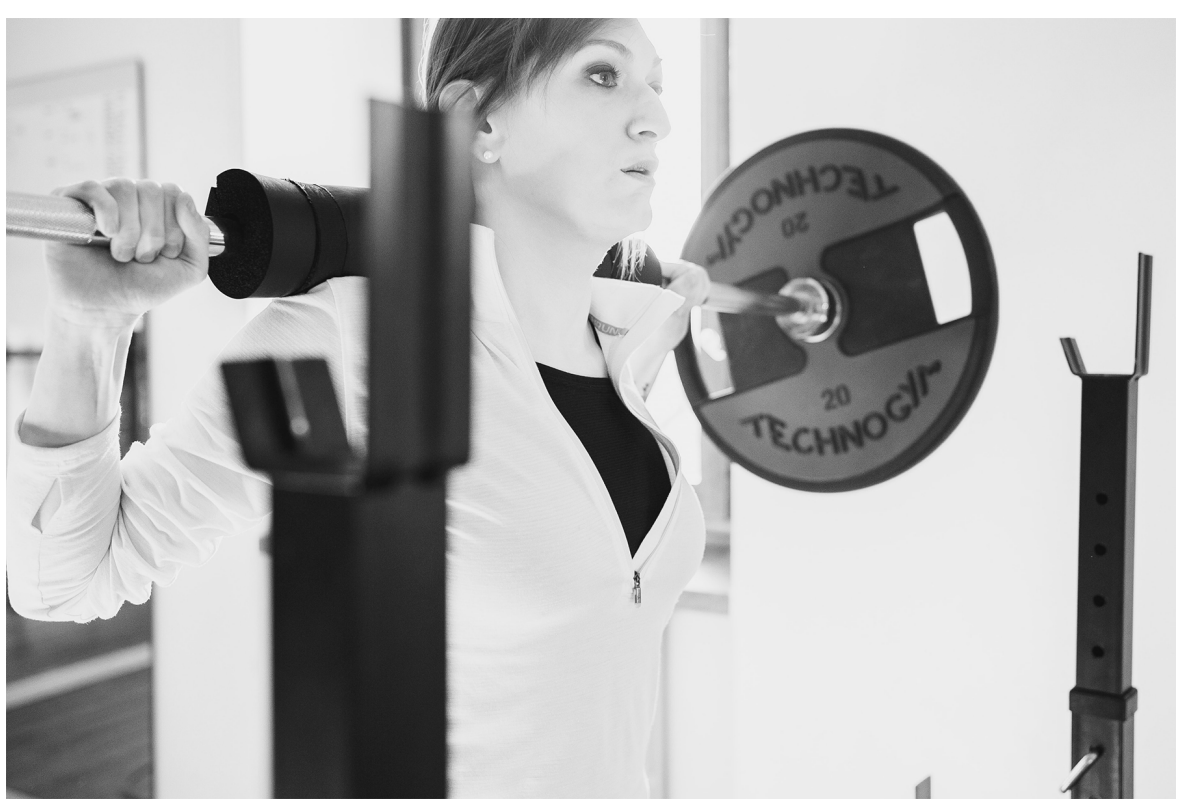

Figure 1 Performing a back squat for developing strength and inducing hypoalgesia. that together we could make it. I trusted him. And we succeeded. We found a way to manage my persistent pain through exposure to movements and exercises which had originally been deemed painful. To begin with, we tested how I responded to different types and doses of exercise. ${ }^{1}$ We worked together with a neurologist who was able to adjust my medication and helped me to realise which types of medication would be most helpful for me. $\mathrm{He}$ was able to share remarkable facts with me about my clinical presentation, explaining terms such as 'allodynia', 'primary and secondary hyperalgesia', 'temporal summation' and 'exercise-induced hypoalgesia'-basically, what I was feeling rather than the diagnoses which, in my opinion, are often just misleading labels. For my type of persistent pain presentation (a mixed type neuropathic-nociplastic ${ }^{2}$ ), anti-inflammatory drugs as well as opioids are at best useless, and at worst harmful.

\section{HOW I AM TODAY}

Nowadays I'm training regularly to feel good (figure 1) and I am still following my neurologist's prescription. Every now and then I feel pain again. It does not disappear completely, or forever; however, now the experience causes me less anguish

\section{MY BREAKTHROUGH}

While I was looking for someone who could help me, I eventually came in contact with a physiotherapist with extensive training in pain and exercise physiology. He spoke of chronic pain knowledgeably, and he was the first person who had done so in 25 years. He said that he would help me and 
because I know where it comes from, what I can do for it and I know that there is someone who can help me. My quality of life is really good now.

\section{FRUSTRATIONS FROM MY JOURNEY}

Looking back at the process I have been through, my first reaction to my new status of well-being is anger. How is it possible to let a person live in the way I lived? No-one truly realises how a person with chronic pain lives. What amazes me is the total lack of empathy that I have experienced as a patient suffering from 'persistent pain'. My kind of pain in particular could not be diagnosed by healthcare professionals because it was not visible with standard diagnostic tests. And just because you do not see it and you cannot touch it, it does not mean it does not exist or is unworthy of note or care. I may not be able to forgive the ignorance of the numerous health professionals I have encountered. Patients with persistent pain should have the right to be believed and treated as suffering human beings with the best available scientific care, not dismissed as mad people.
My final question for you, healthcare professionals, is: should you cure your ignorance first?

\section{THREE BITS OF ADVICE}

1. Trust your patients' narrative, even if you cannot see their pain in standard clinical tests. The poor association between imaging findings and pain highlights the multidimensional complexity of pain presentations and the importance of identifying the type of pain prior to treatment planning.

2. Exercise is an effective treatment for persistent pain. A sufficient intensity and dosage should be appropriately tailored to the patient's profile.

3. Prescribe medications wisely. Make sure that the medication you may prescribe follows the best current available evidence for the patient in front of you, without any short- or long-term risk.

Acknowledgements I wish to thank Luca Maestroni for reviewing the content and grammar of this manuscript.

Contributors I am the only author of this article.
Funding The authors have not declared a specific grant for this research from any funding agency in the public, commercial or not-for-profit sectors.

Competing interests None declared.

Patient consent for publication Obtained.

Provenance and peer review Not commissioned; externally peer reviewed.

(C) Author(s) (or their employer(s)) 2020. No commercial re-use. See rights and permissions. Published by BMJ.

D) Check for updates

To cite Gusmini C. Br J Sports Med 2020;54:753-754.

Accepted 4 September 2019

Published Online First 13 September 2019

Br J Sports Med 2020;54:753-754.

doi:10.1136/bjsports-2019-101038

ORCID iD

Chiara Gusmini http://orcid.org/0000-0002-8317-1379

\section{REFERENCES}

1 Rice D, Nijs J, Kosek E, et al. Exercise-induced hypoalgesia in pain-free and chronic pain populations: state of the art and future directions. J Pain 2019. doi:10.1016/j.jpain.2019.03.005. [Epub ahead of print: $21 \mathrm{Mar} 2019]$.

2 Kosek E, Cohen M, Baron R, et al. Do we need a third mechanistic descriptor for chronic pain states? Pain 2016;157:1382-6. 